\title{
Imaging Invasion: Micro-CT imaging of adamantinomatous craniopharyngioma highlights cell type specific spatial relationships of tissue invasion
}

\author{
John R. Apps ${ }^{1,2 \dagger}$, J. Ciaran Hutchinson ${ }^{1,2^{*} \dagger}$, Owen J. Arthurs ${ }^{2}$, Alex Virasami ${ }^{2}$, Abhijit Joshi ${ }^{3}$, Berit Zeller-Plumhoff ${ }^{4}$, \\ Dale Moulding ${ }^{1}$, Thomas S. Jacques ${ }^{1,2}$, Neil J. Sebire ${ }^{1,2}$ and Juan Pedro Martinez-Barbera ${ }^{1}$
}

\begin{abstract}
Tissue invasion and infiltration by brain tumours poses a clinical challenge, with destruction of structures leading to morbidity. We assessed whether micro-CT could be used to map tumour invasion in adamantinomatous craniopharyngioma (ACP), and whether it could delineate ACPs and their intrinsic components from surrounding tissue. Three anonymised archival frozen ACP samples were fixed, iodinated and imaged using a micro- $C T$ scanner prior to the use of standard histological processing and immunohistochemical techniques.

We demonstrate that micro-CT imaging can non-destructively give detailed 3D structural information of tumours in volumes with isotropic voxel sizes of 4-6 microns, which can be correlated with traditional histology and immunohistochemistry.

Such information complements classical histology by facilitating virtual slicing of the tissue in any plane and providing unique detail of the three dimensional relationships of tissue compartments.
\end{abstract}

Tissue invasion and infiltration by brain tumours poses a clinical challenge, with destruction of eloquent structures leading to morbidity, and the inability to separate tumour and normal tissue limiting the ability to perform a complete surgical resection required for cure.

Microfocus Computed Tomography (Micro-CT) is an emerging technique developed to provide very high resolution imaging of biological specimens. Although designed for the engineering industry (for non-destructive testing of components) and used for archaeological specimens, recent use in small animal phenotyping suggests it could have a role in ex-vivo human tissue evaluation, preserving tissue integrity and allowing subsequent histological examination [1-4].

Adamantinomatous craniopharyngiomas (ACP) contain several different cellular compartments of different cellular density (including palisading epithelium, stellate

\footnotetext{
* Correspondence: Ciaran.Hutchinson@gosh.nhs.uk

${ }^{\dagger}$ Equal contributors

${ }^{1}$ Institute of Child Health, University College London, London, UK

${ }^{2}$ Great Ormond Street Hospital, London, UK

Full list of author information is available at the end of the article
}

reticulum, epithelial whorls/clusters and "wet keratin") and a complex pattern of invasion, such as finger like protrusions of tumour within an often florid glial tissue reaction [5]. As Micro-CT imaging of tissues relies on differential X-ray absorption between tissue components, we assessed whether micro-CT could be used to delineate ACPs and their intrinsic components.

Three anonymised archival primary frozen ACP samples (two paediatric, one adult, Additional file 1: Table S1) were fixed in $10 \%$ formalin and then placed in potassium tri-iodide for at least 72 hours to improve CT contrast. Images were acquired using a Nikon XTH225 ST microCT scanner. After imaging samples were embedded in paraffin and processed by standard protocols, including staining with Haematoxylin and Eosin and immunohistochemistry for glial fibrillary acidic protein (GFAP) and beta-catenin. The results are provided in Figs. 1 and 2 and Additional file 2: Video 1, Additional file 3: Video 2, Additional file 4: Video 3 and Additional file 5: Video 4.

We demonstrate that micro-CT imaging can nondestructively give detailed $3 \mathrm{D}$ structural information of 

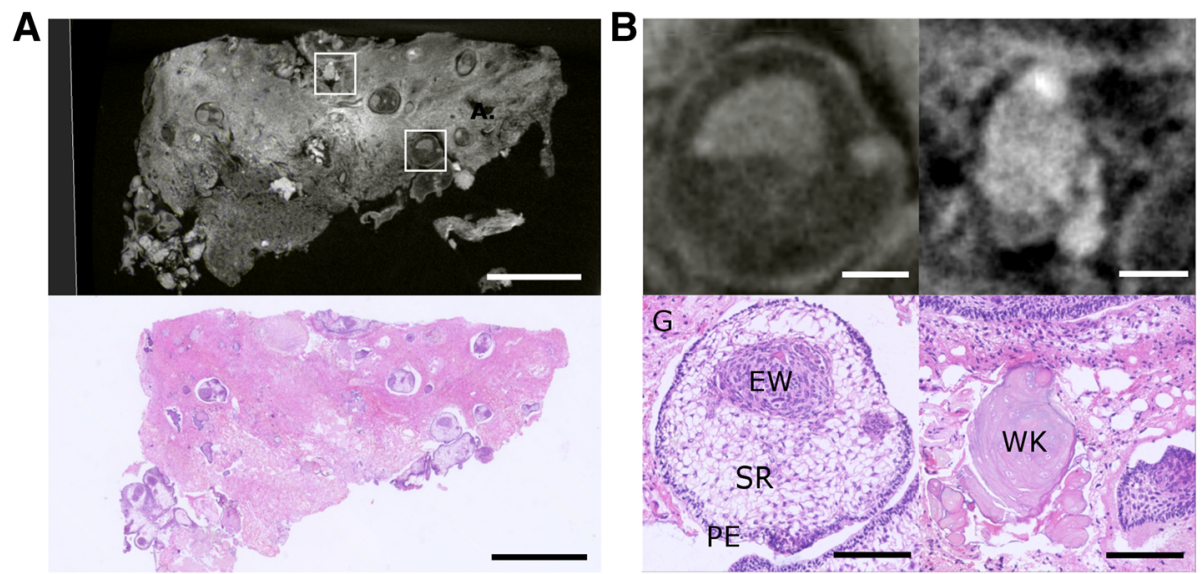

Fig. 1 Micro-CT imaging of adamantinomatous craniopharyngioma: a Virtual and matched histological tissue section of ACP case 1 showing areas of tumour interspersed by reactive glial tissue. Scale bar indicates $1 \mathrm{~mm}$. b 20x images of specific tumour compartments from boxed regions of A. The left panel shows epithelial whorls ("Clusters") within an area of tumour and the right panel shows "wet keratin" which has a higher grey value on CT imaging. Scale bars indicate $100 \mu \mathrm{m}$. EW = Epithelial Whorls, SR=Stellate Reticulum, PE = Palisading Epithelium, G= Reactive Glial Tissue, WK = Wet Keratin

tumours in volumes with isotropic voxel sizes of $4-$ $6 \mu \mathrm{m}$ (equivalent to a resolution of 5-7 $\mu \mathrm{m}$ when taking account of the focal spot size of $3 \mu \mathrm{m}$ [6]) with excellent internal contrast, equivalent to that of low power histological examination (Fig. 1, Additional file 2: Video 1, Additional file 3: Video 2 and Additional file 4: Video 3). Micro-CT image slices could be correlated with their histological counterparts (Fig. 1). Such information complements classical histology by facilitating virtual slicing of the tissue in any plane and providing unique detail of the three dimensional relationships of tissue compartments (Additional file 2: Video 1, Additional file 3: Video 2 and Additional file 4: Video 3).
The majority of ACPs harbour somatic activating CTNNB1 mutations, but surprisingly, on immuno-staining, nuclear-cytoplasmic accumulation of beta-catenin is frequently restricted to a minority of cells, often grouped into "clusters" which mostly correlate to dense epithelial whorls [5]. Evidence from mouse models suggests a key role for these clusters in tumour initiation and/or progression. Genetically engineered mouse models have demonstrated that clusters secrete a plethora of growth factors and cytokines and a murine xenograft model has revealed that clusters at the leading edge of tumour invasion may be responsible for the infiltrative behaviour [7-10]. The spatial relationship of these clusters to tumour infiltration was
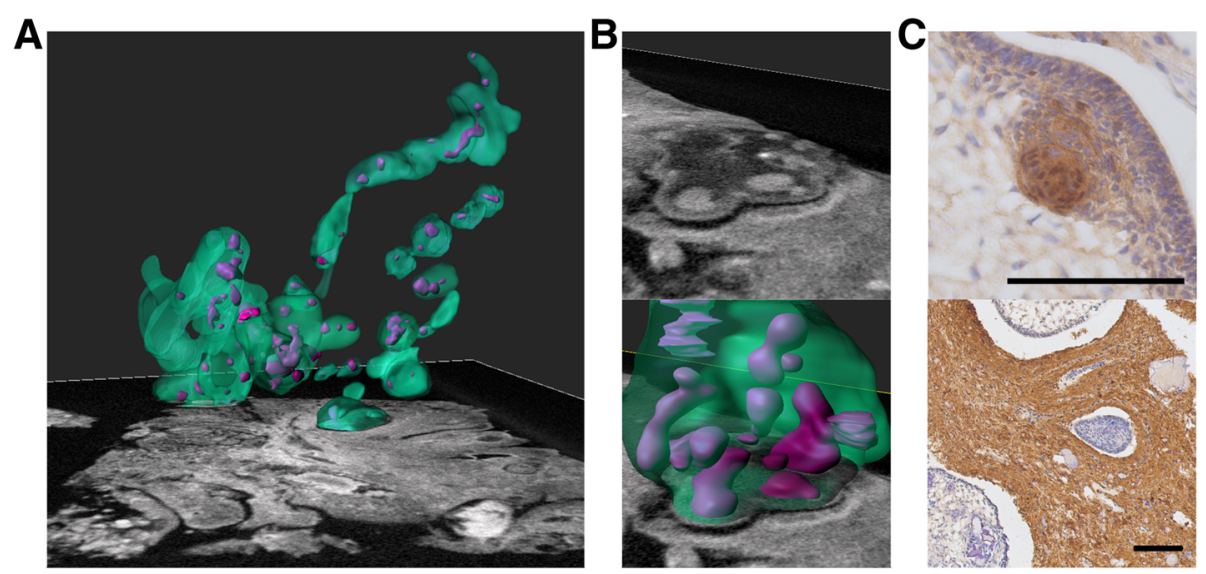

Fig. 2 a Three dimensional annotation of an area of case 1. Green indicates the border of tumour demonstrating nodules and islands with some interconnections. Connections of less than $5 \mu \mathrm{m}$ will not be well visualised at this resolution, possibly explaining discontinuities. Purple indicates epithelial whorls/clusters. b An area of finger-like protrusions. The upper panel shows the micro-CT image; the lower panel shows 3D annotation revealing a complex 3D structure in this region. $\mathbf{c}$ Immuno-histochemical staining of the post micro-CT samples in (A) demonstrating appropriate antigenic reactivity following iodination. Upper panel beta-catenin showing a cluster with nucleo-cytoplasmic accumulation (case 3), lower panel glial fibrillary acidic protein (GFAP) (case 1). Scale bars indicate $100 \mu \mathrm{m}$ 
further explored in 3D by utilising advanced semiautomated image processing software (Imaris (Bitplane AG) and VG Studio MAX (Volume Graphics GmbH)) to extract contour lines for both tumour and clusters from the microCT image stacks. Differential grey values allowed tumour boundaries and clusters to be segmented from reactive glial tissue within manually determined regions. Segmentation tools merged the largest connected areas bounded by the maximum intensity of voxels within a user-defined range, creating a three dimensional model (Fig. 2a \& b). This highlighted the complex relationships of tumour and reactive tissue with nodules and islands interspersed across a region of the sample. An area of apparent "finger like protrusions" was further analysed and found to be part of a relatively larger complex area of tumour tissue (Fig. 2b). Clusters were visualised predominantly at protrusions of tumour in both areas assessed, consistent with their suggested role in promoting invasion (Fig. 2a and b).

Micro-CT is a non-destructive technique that does not preclude subsequent histological processing or staining. All diagnostic features were preserved and immunostaining successful following potassium tri-iodine staining (Fig. 2c), and we found similar imaging features following paraffin embedding (Additional file 5: Video 4).

We present the first 3D assessment of the cellular relationships involved in tumour infiltration using micro-computed tomography (Micro-CT) imaging. As pathology slowly enters the digital era techniques such as micro-CT have the potential to revolutionise the way tissues, and tumour invasion, may be visualised and understood in $3 \mathrm{D}$ at a resolution previously unachievable by other imaging modalities.

\section{Additional files}

Additional file 1: Table S1. Case Details. (DOC $27.5 \mathrm{~kb}$ )

Additional file 2: Video 1. Virtual dissection of a human adamantinomatous craniopharnygioma specimen (case 1) by micro- $C T$ imaging. Nodules and islands of tumour are visible within reactive glial tissue. Epithelial whorls/clusters are present. Areas of "wet keratin" have higher grey level values (appear whiter). The micro- $C T$ isotropic voxel size achieved in each case was related to the degree of magnification achieved and is $4.22 \mu \mathrm{m}$ for this case. (WMV $191950 \mathrm{~kb}$ )

Additional file 3: Video 2. Virtual dissection of a human adamantinomatous craniopharnygioma specimen (case 2) by micro-CT imaging. Nodules and islands of tumour are visible within reactive glial tissue. Epithelial whorls/clusters are not a prominent feature in this case. Areas of "wet keratin" have higher grey level values (appear whiter). The micro-CT isotropic voxel size achieved in each case was related to the degree of magnification achieved and is $4.5 \mu \mathrm{m}$ for this case. (WMV $151528 \mathrm{~kb}$ )

Additional file 4: Video 3. Virtual dissection of a human adamantinomatous craniopharnygioma specimen (case 3) by micro-CT imaging. Nodules and islands of tumour are visible within reactive glial tissue. Epithelial whorls/clusters are present. Areas of "wet keratin" have higher grey level values (appear whiter). The micro-CT isotropic voxel size achieved in each case was related to the degree of magnification achieved and is $6.8 \mu \mathrm{m}$ for this case. (WMV $105536 \mathrm{~kb}$ )
Additional file 5: Video 4. Virtual dissection of case 1 by micro-CT imaging showing epithelial whorls within the tumour and other features persist following embedding in paraffin. Isotropic voxel size was $5.69 \mu \mathrm{m}$. (WMV $79450 \mathrm{~kb}$ )

\section{Abbreviations}

ACP: adamantinomatous craniopharyngioma; GFAP: glial fibrillary acidic protein; Micro-CT: Microfocus Computed Tomography.

\section{Acknowledgements}

This article presents independent research funded by the National Institute for Health Research (NIHR). OJA is funded by an NIHR Clinician Scientist Fellowship award, NJS by an NIHR Senior Investigator award. JCH, OJA and NJS are supported by the Great Ormond Street Hospital Biomedical Research Centre and Great Ormond Street Hospital Children's Charity. JRA is funded by a Cancer Research UK Clinical Research Training Fellowship. JPMB is funded by the Medical Research Council (MRC/M000125/1). Image processing and analysis was undertaken at UCL ICH imaging facility. Nikon Metrology advised regarding acquisition and reconstruction of $C T$ volumes. Optimal analysis and display of CT images was assisted by Volume Graphics $\mathrm{GmbH}$. We thank the CCLG Tissue Bank for access to samples, and contributing CCLG Centres, including members of the ECMC Paediatric network. The CCLG Tissue Bank is funded by Cancer Research UK and CCLG.

\section{Authors' contributions}

JRA conceived the study with JPMB, wrote the paper, obtained tissue samples and performed segmentation of data. JCH developed the study, wrote sections of the paper, performed/interpreted micro-CT scans and performed segmentation of data. OJA interpreted micro-CT data and revised the manuscript. AV performed immunohistochemistry and pathological processing/sectioning. AJ provided tissue samples and revised the manuscript. BZP provided micro-CT parameters and protocols for specimens in paraffin blocks. DM assisted with data segmentation in Imaris and creation of figures. TSJ interpreted histology \& immunohistochemistry and revised the manuscript. NJS interpreted micro-CT data and revised the manuscript. JPMB intellectually conceived the study with JRA, revised the manuscript and oversaw its development. All authors read and approved the final manuscript.

\section{Competing interests}

The authors declare they have no conflicts of interest. JCH, OJA, NJS have academic collaboration agreements with Nikon Metrology (Tring, UK) and Volume Graphics GmbH (Heidelberg, Germany).

Informed consent

Where required consent was obtained from all individual participants included in the study.

\section{Ethical approval}

All procedures performed in studies involving human participants were in accordance with the ethical standards of the institutional and/or national research committee and with the 1964 Helsinki declaration and its later amendments or comparable ethical standards.

\section{Author details}

${ }^{1}$ Institute of Child Health, University College London, London, UK. ${ }^{2}$ Great Ormond Street Hospital, London, UK. ${ }^{3}$ Department of Histopathology, Royal Victoria Infirmary, Newcastle, England. ${ }^{4} \mathrm{MV} I \mathrm{~S} X$-ray Imaging Centre, Faculty of Engineering and the Environment, University of Southampton, Southampton, UK.

Received: 30 March 2016 Accepted: 3 May 2016

Published online: 03 June 2016

References

1. Freeth T, Bitsakis $Y$, Moussas $X$, Seiradakis $J H$, Tselikas A, Mangou H, Zafeiropoulou M, Hadland R, Bate D, Ramsey A, Allen M, Crawley A, Hockley P, Malzbender T, Gelb D, Ambrisco W, Edmunds MG. Decoding the ancient Greek astronomical calculator known as the Antikythera Mechanism. Nature. 2006;444:587-91. doi:10.1038/nature05357. 
2. Metscher BD. MicroCT for developmental biology: a versatile tool for highcontrast 3D imaging at histological resolutions. Dev Dyn. 2009;238:632-40. doi:10.1002/dvdy.21857.

3. Scott AE, Vasilescu DM, Seal KA, Keyes SD, Mavrogordato MN, Hogg JC, Sinclair I, Warner JA, Hackett TL, Lackie PM. Three dimensional imaging of paraffin embedded human lung tissue samples by micro-computed tomography. PLoS One. 2015;10, e0126230. doi:10.1371/journal.pone. 0126230.

4. Tang R, Buckley JM, Fernandez L, Coopey S, Aftreth O, Michaelson J, Saksena M, Lei L, Specht M, Gadd M, Yagi Y, Rafferty E, Brachtel E, Smith BL. Micro-computed tomography (Micro-CT): a novel approach for intraoperative breast cancer specimen imaging. Breast Cancer Res Treat. 2013;139:311-6. doi:10.1007/s10549-013-2554-6.

5. Martinez-Barbera JP, Buslei R. Adamantinomatous craniopharyngioma: pathology, molecular genetics and mouse models. J Pediatr Endocrinol Metab. 2015;28:7-17. doi:10.1515/jpem-2014-0442.

6. Rueckel J, Stockmar M, Pfeiffer F, Herzen J. Spatial resolution characterization of a X-ray microCT system. Appl Radiat Isot. 2014;94:230-34. doi:10.1016/j.apradiso.2014.08.014.

7. Andoniadou CL, Gaston-Massuet C, Reddy R, Schneider RP, Blasco MA, Le Tissier P, Jacques TS, Pevny LH, Dattani MT, Martinez-Barbera JP. Identification of novel pathways involved in the pathogenesis of human adamantinomatous craniopharyngioma. Acta Neuropathol. 2012;124:259-71. doi:10.1007/s00401-012-0957-9

8. Andoniadou CL, Matsushima D, Mousavy Gharavy SN, Signore M, Mackintosh Al, Schaeffer M, Gaston-Massuet C, Mollard P, Jacques TS, Lee Tissier P, Dattani MT, Pevny LH, Martinez-Barbera JP. Sox2(+) stem/ progenitor cells in the adult mouse pituitary support organ homeostasis and have tumor-inducing potential. Cell Stem Cell. 2013;13:433-45. doi:10. 1016/j.stem.2013.07.004.

9. Martinez-Barbera JP. 60 Years of neuroendocrinology: biology of human craniopharyngioma: lessons from mouse models. J Endocrinol. 2015;226: T161-72. doi:10.1530/JOE-15-0145.

10. Stache C, Holsken A, Schlaffer SM, Hess A, Metzler M, Frey B, Fahlbusch R, Flitsch J, Buchfelder M, Buslei R. Insights into the infiltrative behavior of adamantinomatous craniopharyngioma in a new xenotransplant mouse model. Brain Pathol. 2015;25:1-10. doi:10.1111/bpa.12148.

\section{Submit your next manuscript to BioMed Central and we will help you at every step:}

- We accept pre-submission inquiries

- Our selector tool helps you to find the most relevant journal

- We provide round the clock customer support

- Convenient online submission

- Thorough peer review

- Inclusion in PubMed and all major indexing services

- Maximum visibility for your research

Submit your manuscript at www.biomedcentral.com/submit

) Biomed Central 